\title{
Insights into Sustainable Development of China's Marine Economy From the Perspective of Biased Technological Progress
}

\author{
Wenhan Ren* \\ Business School, Qingdao University, Qingdao, Shandong, 266000, PR China
}

Received: 8 October 2020

Accepted: 26 November 2020

\begin{abstract}
Based on the Malmquist-total factor productivity index decomposition method, this study incorporates marine energy, capital, and labour into a research framework to measure the marine input-biased technological progress index and its bias effect in various coastal regions of China. Through the change in the proportion of factor inputs, this study further judges the bias of the factor allocation of marine technological progress, and systematically investigates the regional differences in the bias of marine technological progress. The results indicate that there is input-biased technological progress in the marine economy, and the biased technological progress in most regions is a stable contributing factor for promoting the improvement of TFP and the development of marine economy. However, with the passage of time, this bias effect is gradually weakened, and China's marine technological progress is gradually deviating from a reasonable allocation structure. Marine technological progress tends to save labour between capital and labour inputs as well as energy and labour inputs, and tends to save energy between capital and energy inputs, but generally prefers to save labour.
\end{abstract}

Keywords: sustainable development, marine economy, biased technological progress, factor endowment, input-biased technological change index

\section{Introduction}

The 21 st century is the century of the ocean, and the development of marine resources and the marine economy have become consensus goals for coastal countries [1-4]. The gross ocean production (GOP) in China, a major maritime country, increased from 951.84 billion yuan in 2001 to 7761.1 billion yuan

*e-mail: qdrenwenhan@163.com in 2017, through a rapid development of the marine economy [5]. The $19^{\text {th }}$ National Congress of the Communist Party of China continued to emphasize the development of the marine economy, and proposed the idea of 'adhering to the overall planning of land and sea and accelerating the construction of a maritime power' [6-7]. However, compared with developed coastal countries worldwide, China's marine economy has experienced weak growth in recent years. According to the 'The United States Coastal and Great Lakes Marine Economic Development Report 2012', the development of the U.S. marine economy in 2012 was far faster 
than that of the U.S. national economy, accounted for $10.5 \%$ of the gross domestic product (GDP), which was more than four times the national economic growth rate (2.5\%) of the U.S. that year. Australia's marine economy has developed rapidly, and the contribution rate of its marine industry to GDP reached $13 \%$, far exceeding those of other economic sectors. However, the Chinese GOP in 2017 increased by $6.9 \%$ over the previous year, accounting for $9.4 \%$ of its GDP. The growth rate of China's marine economy has been much lower than that for developed coastal countries. The output growth of marine economy comes from the increase in factor input and unit input-output. At present, the factor input of the marine economy is becoming progressively tighter and it is difficult to achieve a substantial increase [8-11]. Moreover, the marginal income of the factor input is negatively correlated with the factor input itself [12]. Therefore, technological progress is an important source of marine economic development, and the level of technological progress represented by total factor productivity (TFP) has become the fundamental source for sustainable growth of China's marine economy [1314].

Technological progress can help reduce energy and resource consumption and environmental pollution and improve factor efficiency [15-17]. Theoretical research and policy discussion has focused on how to guide energy savings and emission reductions through technological progress [18-21]. For many years, under the guidance of neoclassical economic theory, research on economic theory and empirical research has assumed that technological progress is neutral. However, under the assumption of neutral technological progress, usually the speed and contribution of technological progress can only be measured, and the characteristics of other aspects of technological progress cannot be analyzed [22-23]. In the process of real economic development, technological progress is not completely neutral, and it is usually biased towards a certain factor [24]. The scenario of 'the faster, the better' does not apply to technological progress [25-26]. Specifically, when the direction of technological progress is consistent with the direction of a factor allocation, the productivity of certain factors will be further improved. The technology at this time must be appropriate, otherwise it will inhibit the growth of factor productivity [27-28]. Therefore, studying technological progress biased towards specific factors or sectors can clarify the nature of endogenous technology and the allocation effect of technological progress, thereby allowing simultaneous achievement of resource conservation and improvement in environmental quality.

According to Hicks' theory, the purpose of technological progress is to conserve scarce production factors and use those that are more abundant [29]. Kennedy (1964) introduced the 'Frontiers of Innovation Possibilities' from the perspective of technology supply [30-31]. The first empirical analysis of the direction of technological progress concluded that technological progress in the United States from 1899 to 1960 was biased towards capital [32]. Other studies have confirmed that technological progress in the United States since the 20th century has generally been biased towards capital [33]. In the 1990s, with the development of endogenous technological change theory, the theory of biased technological progress was presented. Subsequently, the direction of technological progress was extended and redefined to include any factor inputs. Acemoglu (2007) examined the impact of different product markets on the direction of technological progress, and believed that technology was biased towards factors with more sufficient supply [34]. Technological progress bias in industries such as manufacturing has been explored in academia. However, there has been minimal consideration of biased technological progress in the marine economy [35-36]. The ocean is the most important industrial carrier in China that reflects the level of technology and acts as the leading force to promote the rapid growth of a nation's economy. Biased technological progress directly affects the sustainable development of the marine economy in China [37]. In this context, based on the Malmquist-total factor productivity index decomposition method, this study incorporates marine energy, capital, and labour into a research framework to measure the marine input-biased technological progress index and its bias effect in various coastal regions of China. These findings can provide guidance for the rational use of resources and sustainable development of the marine economy.

\section{Materials and Methods}

\section{Measuring Biased Technological Progress}

The reciprocal of the input-oriented distance function defined by Shephard (1953) is the ratio between the minimum factor inputs required for a given output and the actual factor inputs [38]. Suppose that $\left.\mathrm{x}^{\mathrm{t}}=\left(x_{1}^{t}, \ldots, x_{N}\right)^{t}\right)$ represents a set of non-negative input vectors in period $t$, and $\mathrm{x}^{\mathrm{t}}=\left(y_{1}{ }^{t}, \ldots, y_{N}{ }^{t}\right)$ represents a set of non-negative output vectors in period $t$. Then, Shephard's input distance function in period $t$ can be defined as follows:

$$
D_{i}^{t}(y, x)=\max \left\{\lambda: \frac{x}{\lambda} \in L^{t}(y)\right\}
$$

...where $L^{t}(y)$ is the input requirement set, which represents the feasible input portfolio needed for this period of output.

Under input orientation, the Malmquist-TFP index proposed by Färe et al. (1994) is defined on the basis of satisfying the conditions of constant returns to scale, and the formula is as follows [39]: 


$$
M I=\sqrt{\frac{D_{0}^{t+1}\left(y^{t}, x^{t}\right)}{D_{0}^{t+1}\left(y^{t+1}, x^{t+1}\right)} \times \frac{D_{0}^{t}\left(y^{t}, x^{t}\right)}{D_{0}^{t}\left(y^{t+1}, x^{t+1}\right)}}
$$

The Malmquist-TFP index can be further decomposed into TECH and EFFCH, using the following formula:

$$
\begin{gathered}
M I=\sqrt{\frac{D_{0}^{t+1}\left(y^{t}, x^{t}\right)}{D_{0}^{t}\left(y^{t}, x^{t}\right)} \times \frac{D_{0}^{t+1}\left(y^{t+1}, x^{t+1}\right)}{D_{0}^{t}\left(y^{t+1}, x^{t+1}\right)}} \\
\times\left[\frac{D_{0}^{t}\left(y^{t}, x^{t}\right)}{D_{0}^{t+1}\left(y^{t+1}, x^{t+1}\right)}\right]=T E C H \times E F F C H
\end{gathered}
$$

TECH index refers to changes in the production frontier itself, and EFFCH index refers to the change in distance between the input-output combination and the production frontier. However, the Malmquist-TFP index is a comprehensive measurement of technological progress performance that includes both the translation and rotation effects of the production frontier; the total effect of both translation and rotation can be expressed by the TECH index. The TECH index proposed by Färe et al (1997) is decomposed as follows [40]:

$$
\begin{gathered}
\text { MATECH }=\frac{D_{0}^{t+1}\left(y^{t}, x^{t}\right)}{D_{0}^{t}\left(y^{t}, x^{t}\right)} \\
\text { OBTECH }=\sqrt{\frac{D_{0}^{t+1}\left(y^{t+1}, x^{t+1}\right)}{D_{0}^{t}\left(y^{t+1}, x^{t+1}\right)} / \frac{D_{0}^{t+1}\left(y^{t+1}, x^{t}\right)}{D_{0}^{t}\left(y^{t+1}, x^{t}\right)}} \\
\text { IBTECH }=\sqrt{\frac{D_{0}^{t+1}\left(y^{t+1}, x^{t}\right)}{D_{0}^{t}\left(y^{t+1}, x^{t}\right)} / \frac{D_{0}^{t+1}\left(y^{t}, x^{t}\right)}{D_{0}^{t}\left(y^{t}, x^{t}\right)}}
\end{gathered}
$$

Among these components, the technological scale change (MATECH) index measures the "translation effect" of the production frontier, that is, neutral technological progress. The output-biased technological change (OBTECH) index measures the enhancement effect of technological progress on the different ratios of outputs; in the case of a single output, the OBTECH index is equal to 1 . The input-biased technological change (IBTECH) index measures the change in the marginal rate of substitution of the different factor inputs from technological progress. This index indicates that technological progress has resulted in further improvement $($ IBTECH $>1)$ or reduction $($ IBTECH $<1)$ of total factor productivity on the basis of the ratios of savings in factor inputs. Therefore, this method can distinguish the rotation effect that may occur on the production frontier.

\section{Distinguishing Biased Technological Progress}

The IBTECH index measures the improvement or deterioration of biased technological progress towards TFP, but does not give a bias for technological progress among different elements. In order to solve this problem, Weber and Domazlicky (1999) proposed a method to distinguish the factor bias in technological progress based on the IBTECH index, achieved by the change in factor proportion in the period from $t$ to $t+1$, and the different combinations between IBTECH and 1 [41].

It is assumed that technological progress has taken place from $t$ to $t+1$. In Fig 1, four equal-product curves $\left(L^{t}(y), L_{\pi}^{t+1}(y), L_{1}^{t+1}(y)\right.$ and $\left.L_{2}^{t+1}(y)\right)$ represent the same output level. Technological progress has brought the last three equal-product curves closer to the origin than $L^{t}(y)$. If the marginal rate of substitution between the two factor inputs remains constant, the technological progress is Hicks neutral, and the equal-product curve is translated, which is expressed by $L_{\pi}^{t+1}(y)$ in Fig. 1. If the marginal rate of substitution between the two factor inputs increases (or decreases) while the input portfolio remains constant, the technological progress uses $x_{1}$ (or using $x_{2}$ ), which is represented by $L_{1}^{t+1}(y)$ (or $\left.{ }_{2}^{t+1}(y)\right) . x^{t}$ and $x^{t+1}$ represent the input combination ratios in periods $t$ and $t+1$, respectively.

According to Fig 1 and the research of Barros and Weber (2009) [42], the following discriminant method can be obtained: In the case of $x_{2}^{t+1} / x_{1}^{t+1}<x_{2}^{t} / x_{1}^{t}$, when IBTECH $>1$, it means that the technological progress uses $x_{1}$; when IBTECH $<1$, it means that the technological progress uses $x_{2}$. When $x_{2}{ }^{t+1} / x_{1}{ }_{1}^{t+1}>x_{2}{ }^{t} / x_{1}{ }^{t}$, the results are the opposite. When IBTECH $=1$, regardless of the input combination ratio, the technological progress is neutral. The above methods can be summarized as in Table 1 .
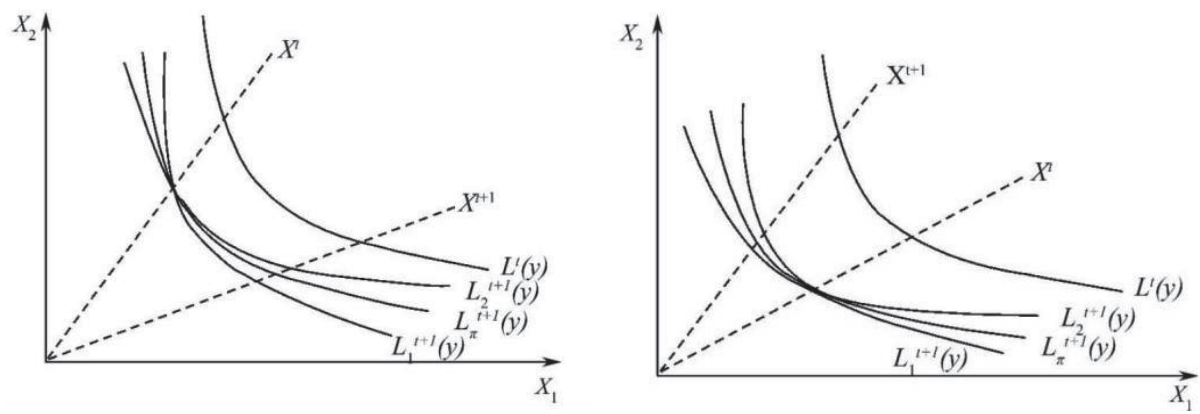

Fig.1. Production frontier and biased technological progress (L: Scenario 1; R: Scenario 2). 
Table 1. The distinguishing method of biased technological progress.

\begin{tabular}{|c|c|c|c|}
\hline Input combination & IBTECH $>1$ & IBTECH $=1$ & IBTECH $<1$ \\
\hline$x_{2}^{t+1} / x_{1}^{t+1}<x_{2}^{t} / x_{1}^{t}$ & Saving $\mathrm{x}_{2}$, using $\mathrm{x}_{1}$ & Neutral & Saving $\mathrm{x}_{1}$, using $\mathrm{x}_{2}$ \\
\hline$x_{2}^{t+1} / x_{1}^{t+1}>x_{2}^{t} / x_{1}^{t}$ & Saving $\mathrm{x}_{1}$, using $\mathrm{x}_{2}$ & Neutral & Saving $\mathrm{x}_{2}$, using $_{1}$ \\
\hline
\end{tabular}

Note: The table is organized according to Weberand and Dotnazlicky (1999).

\section{Data and Variables}

This research used marine economic data of 11 coastal regions in China from 2006 to 2016. These data mainly come from 'China Statistical Yearbook', 'China Marine Statistical Yearbook', and 'the Statistical Communique of Chinese Marine Economy'. The government of China made three adjustments to the marine economic statistics before 2006, thereby resulting in inconsistent statistical calibres of the data and an inability to make scientific comparisons [43]. Therefore, the research period of this article starts in 2006.

\section{Input Variables}

\section{(1) Capital input $(\mathrm{K})$}

This study uses the stock of marine capital as an indicator of capital input. Because there is no statistical data on the marine capital stock of coastal regions, this research estimates the total capital stock of each coastal region in China, and then revises the marine capital stock in accordance with the proportion of GOP to GDP in the coastal regions. Usually, a perpetual inventory or Kaldor's methods are used to determine capital stock, and this study uses the former.

$$
K_{\mathrm{it}}=I_{\mathrm{it}} / \mathrm{P}_{\mathrm{it}}+1-\delta \quad K_{\mathrm{i}, \mathrm{t}-1} \delta=9.6 \%
$$

...where $K_{\mathrm{it}}$ represents the capital stock of the $i$ province in $t$ period, $K_{\mathrm{i},-1}$ represents the capital stock of the $i$ province in $t-1$ period, $I_{\mathrm{it}}$ is the investment of the current year, expressed by the completion amount of fixed assets, $P_{\text {it }}$ is the fixed asset investment price index of each province in that year, and $\delta$ represents the depreciation rate of the total fixed asset formation, using $9.6 \%$ as the fixed depreciation rate. Finally, the marine capital stock is rendered equal to the ratio of the GOP to the GDP of coastal regions as multiplied by the capital stock of coastal regions [44].

(2) Labour input (L)

The number of employees involved in maritime activities is selected as the labour input. To improve data stability and consistency, the labour input data is processed smoothly, i.e. data from the first and last year remains unchanged, while the rest of the data points are processed by calculating the mean of the data for each year with that of the years immediately before and after the target year.

\section{(3) Energy input (E)}

This study uses the amount of energy consumption of the marine economy in a coastal province. As the energy consumption of a marine economy cannot be obtained directly from the yearbook, all types of energy consumed in coastal regions are first converted into standard coal units to obtain the overall energy consumption of each region. Then, the marine energy input is equal to the ratio of the GOP to the GDP of coastal regions multiplied by the energy consumption (standard coal) in each province.

\section{Output Variables}

In this paper, GOP is selected as the output variable of the model. In order to avoid the impact of inflation and price level on the measurement results, the constant price level of GOP in each region is converted based on 2006 [45].

\section{Results and Discussion}

\section{The IBTECH Index for China's Marine Economy}

Because the IBTECH index is a link index, for convenience, the IBTECH index of marine economy in 2006-2007 is defined as the IBTECH index in 2007, which is also defined in other years in turn. The IBTECH index evaluates technological progress driven by factor inputs under a constant output; the higher the index, the greater the technological progress. From a national perspective, the annual values of the IBTECH index were greater than 1 , which proved that the biased technological progress became a more stable contributing factor in promoting the improvement of TFP and the development of the marine economy. The deviation of the index dropped from 0.0769 in 2007 to 0.0458 in 2016, which indicated that China's marine technological progress may have deviated from the desired factor configuration structure, or that the factor structure had gradually failed to meet the needs of technological progress. Experience shows that the appropriate technology of a country or region is not necessarily advanced, but it should match with the local factor endowment. Therefore, in the process of marine economic development, China should make appropriate technological choices according to their 
Table 2. The IBTECH index of marine economy for China's coastal regions from 2006 to 2014.

\begin{tabular}{|c|c|c|c|c|c|c|c|c|c|}
\hline & $\begin{array}{c}2006- \\
2007\end{array}$ & $\begin{array}{c}2007- \\
2008\end{array}$ & $\begin{array}{c}2008- \\
2009\end{array}$ & $\begin{array}{c}2009- \\
2010\end{array}$ & $\begin{array}{c}2010- \\
2011\end{array}$ & $\begin{array}{c}2011- \\
2012\end{array}$ & $\begin{array}{c}2012- \\
2013\end{array}$ & $\begin{array}{c}2013- \\
2014\end{array}$ & Geomean \\
\hline Tianjin & 1.0708 & 1.0538 & 1.0658 & 1.1410 & 1.0563 & 1.0291 & 0.9985 & 1.0059 & 1.0518 \\
\hline Hebei & 1.0718 & 1.0979 & 0.8692 & 1.0979 & 1.1111 & 1.0806 & 1.0651 & 1.1245 & 1.0617 \\
\hline Liaoning & 1.0897 & 1.0900 & 1.0473 & 1.0570 & 1.1156 & 1.0265 & 1.0692 & 1.0503 & 1.0679 \\
\hline Shanghai & 1.0342 & 1.0756 & 1.0103 & 1.0941 & 1.0432 & 1.0310 & 1.0289 & 1.0059 & 1.0400 \\
\hline Jiangsu & 1.1503 & 1.0401 & 1.1032 & 1.0814 & 1.0493 & 1.0264 & 0.9831 & 1.0272 & 1.0565 \\
\hline Zhejiang & 1.0520 & 1.0408 & 1.0991 & 1.0141 & 1.0291 & 1.0153 & 1.0056 & 0.9905 & 1.0304 \\
\hline Fujian & 1.0853 & 1.0449 & 1.0620 & 1.0249 & 1.0286 & 0.9896 & 1.0221 & 1.0788 & 1.0416 \\
\hline Shandong & 1.1050 & 1.0924 & 1.0499 & 1.0993 & 1.0799 & 1.0684 & 1.0533 & 1.0933 & 1.0800 \\
\hline Guangdong & 1.0431 & 1.1684 & 1.0928 & 1.1251 & 1.0796 & 1.1109 & 1.0656 & 1.1097 & 1.0988 \\
\hline Guangxi & 1.0855 & 1.1274 & 1.1312 & 1.1070 & 1.0100 & 1.0900 & 1.0320 & 1.0436 & 1.0775 \\
\hline Hainan & 1.0624 & 1.0388 & 1.0428 & 1.0222 & 1.0607 & 1.0359 & 1.0417 & 0.9854 & 1.0360 \\
\hline Geomean & 1.0769 & 1.0784 & 1.0499 & 1.0778 & 1.0598 & 1.0452 & 1.0328 & 1.0458 & \\
\hline
\end{tabular}

own resource endowment characteristics so that technology and capital, labour, energy can be more closely matched, thereby further strengthening the role of technological progress in promoting TFP and marine economic growth. From a regional perspective, the annual values of the IBTECH index were greater than 1 in most regions from 2007 to 2016, which was consistent with the overall national trend. However, there was a difference in the IBTECH index for China's coastal regions. The IBTECH index was high in the provinces of Guangdong and Shandong, at 1.0988 and 1.0800 , respectively. However, it was low in Zhejiang and Hainan, at only 1.0304 and 1.0360 , respectively. In addition, many regions experienced fluctuations in the IBTECH index during the study period.

\section{Factor Bias of Technological Progress in China's Marine Economy}

Overall, the factor input of technological progress in most regions tends to use capital intensively, and the strength of biased technological progress follows the trend capital $>$ energy $>$ labour. From the regional point of view, the direction of marine biased technology progress in each region during the sample period was roughly the same, with a preference for an intensive use of the capital factor. Specifically, the technological progress of the marine economy between capital and labour is biased towards minimizing labour and using capital. China itself is a country with relatively abundant labour resources, but in recent years, the direction of China's marine technological progress has moved towards capital input, which is contrary to our intuition. Capitalbiased technological progress has promoted the rapid growth of China's marine economy for many years. However, with the release of this kinetic energy and the change in factor endowment structure, a structural contradiction caused by capital-biased technological progress began to appear. The role of capital in the late production process is increasingly declining, resulting in inefficient capital allocation, and the problem of overcapacity is highlighted. Although this trend has yet to exert a negative impact on growth in productivity of China's marine economy, it will eventually threaten this economy's sustainable development if the state does not take effective measures to address these problems. The technological progress between capital and energy is biased towards saving energy and using capital. At present, there is no overall strategic planning at the national level for development concerning the utilisation of marine energy in China. Especially in some disputed territorial waters, there is a lack of coordination between diplomatic plans and resource development plans. It will take a long time to overcome limitations of technology, human resources, environmental pollution, and policy related to the development of marine energy, which is why technological progress in China's marine economy is now biased towards the use of capital rather than energy. Technological progress between energy and labour is biased towards saving labour and using energy, except in 2013. This is mainly due to rapid rates of construction and lack of technical experience in China's marine labour force, which does not meet the requirements of new technologies and methods for development of marine industries. Marine industries have a high demand for professional marine labour, such as senior marine science specialists, senior marine management personnel, and technical experts, but this kind of labour is scarce. In addition, the phenomenon of marine labour loss is quite serious and has resulted in inappropriate distribution of marine labour. If such a cycle continues, it will seriously affect the effective 


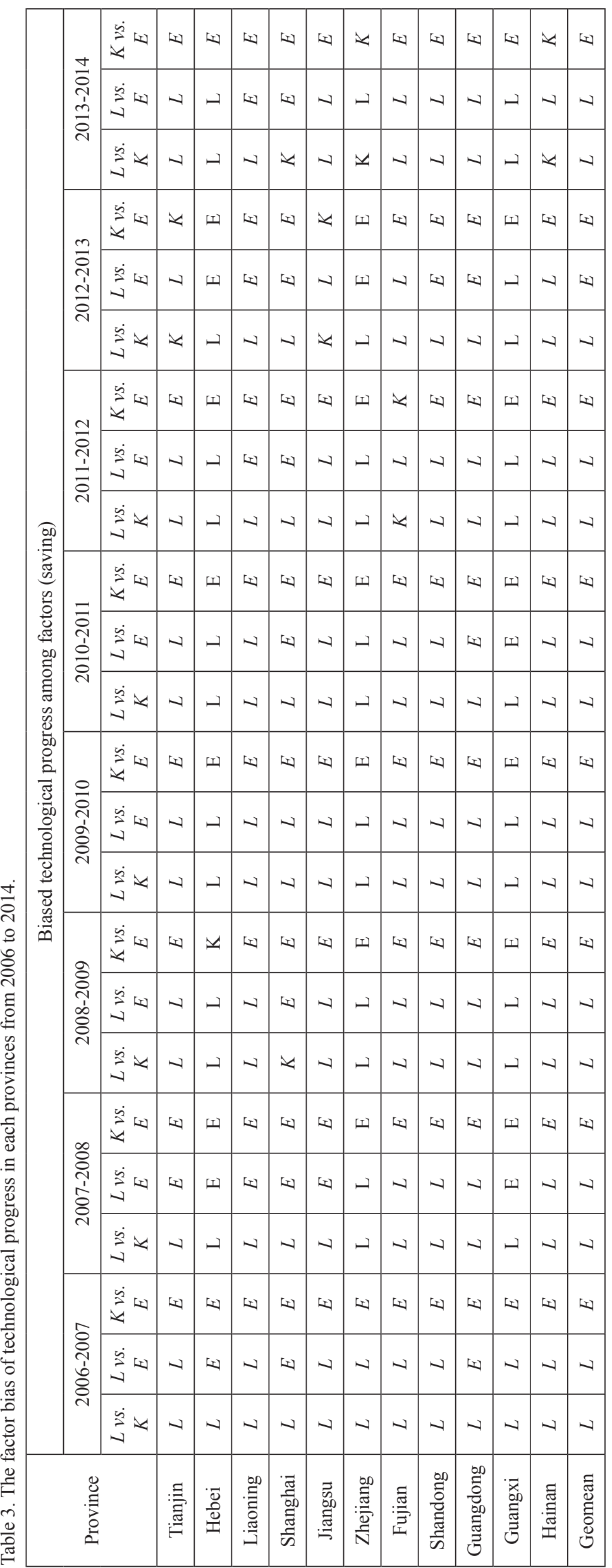


allocation of marine labour and damage the long-term prospects of sustainable development of the marine industry.

\section{Conclusions}

Biased technological progress is an important breakthrough in realizing the coordinated and sustainable development of marine economic growth in concert with resources and environment. Based on the Malmquist-total factor productivity index decomposition method, this study incorporates marine energy, capital, and labour into a research framework to measure the marine input-biased technological progress index and its bias effect in various coastal regions of China. Through the change in the proportion of factor inputs, this study further judges the bias of the factor allocation of marine technological progress, and systematically investigates the regional differences in the bias of marine technological progress. The results indicate that there is input-biased technological progress in the marine economy, and the biased technological progress in most regions is a stable contributing factor for promoting the improvement of TFP and the development of marine economy. However, with the passage of time, this bias effect is gradually weakened, and China's marine technological progress is gradually deviating from a reasonable allocation structure. Marine technological progress tends to save labour between capital and labour inputs as well as energy and labour inputs, and tends to save energy between capital and energy inputs, but generally prefers to save labour. The deepening of marine capital and technological progress in China have a 'crowding out' effect on labour. Different regions show different characteristics of the input bias for marine technological progress, but the paths of biased technological progress in different regions are generally the same.

The empirical results have practical implications for policy making:

(1) At present, there is a certain distortion in the price of production factors in China's marine economy. The price of production factors cannot accurately reflect the actual value of production factors, the inputs of production factors cannot be reasonably rewarded, and the remuneration of workers is low. Capital often stays idle in the financial system, which makes it difficult for funds to flow into the marine economy. Therefore, the state should adhere to the decisive role of the market in the allocation of factor resources, and use the market to allocate marine factor resources reasonably, so that both the factor supplier and the factor demander can benefit from the factor market, thereby ensuring the normal development of the marine factor market.

(2) China's marine economic resource endowment has relatively abundant labour and a relative lack of capital. However, the results of this study demonstrate that marine technological progress is inclined to capital, which is inconsistent with the abundant labour situation in China. Therefore, the state should pay more attention to professionally training marine labour, realise the capitalisation of knowledge, improve cooperation between production and research, and actively coordinate the relationship between factor resource endowments and technological innovation, so that marine biased technological progress can return to a direction suitable for China's national conditions and sustainable development of the marine economy can be realized.

\section{Acknowledgements}

This work was supported by The National Social Science Fund of China [grant number 20CJY022]; and Qingdao Philosophy and Social Science Planning Project [grant number QDSKL2001063].

\section{Conflicts of Interest}

The authors declare no conflict of interest.

\section{References}

1. STEBBINGS E., PAPATHANASOPOULOU E., HOOPER T., AUSTEN M.C., YAN X.Y. The marine economy of the United Kingdom. Marine Policy. 116, 103905, 2020.

2. LI B., TIAN C., SHI Z.Y., HAN Z.L. Evolution and differentiation of high-quality development of marine economy: A case study from China. Complexity. 3, 1, 2020.

3. GAO P.F. The financial support for the development of marine economy. Journal of Coastal Research. 107, 169, 2020.

4. ZHANG X.Y., ZHU F.Y., LI Y. Marine resources accounting: A diversification of subject-based study. Journal of Coastal Research. 106, 5, 2020.

5. REN W., WANG Q., JI J. Research on China's marine economic growth pattern: An empirical analysis of China's eleven coastal regions. Marine Policy. 87, 158, 2018.

6. REN W.H., JI J.Y., CHEN L., ZHANG Y. Evaluation of China's marine economic efficiency under environmental constraints - An empirical analysis of China's eleven coastal regions. Journal of Cleaner Production. 184, 806, 2018.

7. YIN K.D., XU Y., LI X.M., JIN X. Sectoral relationship analysis on China's marine-land economy based on a novel grey periodic relational model. Journal of Cleaner Production. 197, 815, 2018.

8. CAO Q., SUN C.Z., ZHAO L.S., CAO W.W., YAN X.L. Marine resource congestion in China: Identifying, measuring, and assessing its impact on sustainable development of the marine economy. Plos One. 15 (1), e0227211, 2020.

9. AN Y.C. Analysis on the sustainable development capacity of China's marine ecosystem from entropy perspective. Journal of Coastal Research. 115, 68, 2020.

10. FONNER R., BELLANGER M., WARLICK A. Economic analysis for marine protected resources management: 
Challenges, tools, and opportunities. Ocean \& Coastal Management. 194, 105222, 2020.

11. ZHANG C., QUAN Y.B., ZHONG H.Y. The building of marine ecological civilization and sustainable development: conference report. 110, 103627, 2019.

12. ZHANG L.P., CAI S.S. Theoretical methods and applications of marine economy and sustainable marine development. Journal of Coastal Research. 103, 581, 2020.

13. ZHANG J., CHANG Y., WANG C., ZHANG L. The green efficiency of industrial sectors in China: A comparative analysis based on sectoral and supply-chain quantifications. Resources, Conservation and Recycling. 132, 269, 2018.

14. YAO J.H. The Development trend of marine economy based on multi-objective decision analysis. Journal of Coastal Research. 94, 613, 2019.

15. RASHIDI K., SAEN R.F. Measuring eco-efficiency based on green indicators and potentials in energy saving and undesirable output abatement. Energy Economics. 50, 18, 2015.

16. CHEN J., WANG S.J., ZHOU C.S., LI M. Does the path of technological progress matter in mitigating China's PM2.5 concentrations? Evidence from three urban agglomerations in China. Environmental Pollution. 254, 113012, 2019.

17. LI Y., WANG Y.H., DING L.L., KE L.J., MA W.Q., YANG Y.L. Dynamic response analysis among environmental regulation, technological progress and water resource consumption in China's textile industry. Polish Journal of Environmental Studies. 29 (4), 2709, 2020.

18. WANG S., SONG M. Influences of reverse outsourcing on green technological progress from the perspective of a global supply chain. Science of The Total Environment. 595, 201, 2017.

19. AN H., XU J.J., MA X.J. Does technological progress and industrial structure reduce electricity consumption? Evidence from spatial and heterogeneity analysis. Structural Change and Economic Dynamics. 52, 206, 2020.

20. YI M., WANG Y.Q., SHENG M.Y., SHARP B., ZHANG Y. Effects of heterogeneous technological progress on haze pollution: Evidence from China. Ecological Economics. 169, 106533, 2020

21. HUANG J.B., CHEN X., YU, K.Z., CAI X.C. Effect of technological progress on carbon emissions: New evidence from a decomposition and spatiotemporal perspective in China. Journal of environmental management. 274, 110953, 2020.

22. LI R., SUN T. Research on impact of different environmental regulation tools on energy efficiency in China. Polish Journal of Environmental Studies. 29 (6), 4151, 2020.

23. LIANG H.J., LIU J.S., WANG R., SONG Y.Q., ZHOU Y.Y. Research on China's regional energy efficiency evaluation and influencing factors based on the DEA-Tobit model. 29 (5), 3691, 2020

24. LI J., SEE K.F., CHI J. Water resources and water pollution emissions in China's industrial sector: A green-biased technological progress analysis. Journal of Cleaner Production. 229, 1412, 2019.

25. GUO L., QUA Y., TSENG M.L. The interaction effects of environmental regulation and technological innovation on regional green growth performance. Journal of Cleaner Production. 162 (20), 894, 2017.

26. SONG M.L., WANG S.H., WU K.Y. Environment-biased technological progress and industrial land-use efficiency in
China's new normal. Annals of Operations Research. 268 (1-2), 425, 2018.

27. WEI Z.X., HAN B.T., HAN L., SHI Y.Y. Factor substitution, diversified sources on biased technological progress and decomposition of energy intensity in China's high-tech industry. Journal of Cleaner Production. 231, 87, 2019.

28. SONG M.L., WANG S.H. Measuring environment-biased technological progress considering energy saving and emission reduction. Process Safety and Environmental Protection. 116, 745, 2018.

29. HICKS J.R. The theory of wages. London: Macmillan, 1932.

30. KENNEDY C. Induced bias in innovation and the theory of distribution. Economic Journal. 74 (295), 541, 1964.

31. SAMUELSON P. A theory of induced innovations along Kennedy-Weisacker lines. Review of Economics and Statistics. 47 (4), 444, 1965.

32. DAVID P.A., VAN DE KLUNDERT T. Biased efficiency growth and capital-labor substitution in the US, 1899-1960. The American Economic Review. 55, 357, 1965.

33. PANIK M.J. Factor learning and biased factor-efficiency growth in the United States, 1929-1966. International Economic Review. 17 (3), 733, 1976.

34. ACEMOGLU D. Equilibrium bias of technology. Econometrica. 75 (5), 1371, 2007.

35. DING L., YANG Y., WANG L., CALIN A.C. Cross efficiency assessment of China's marine economy under environmental governance. Ocean \& Coastal Management. 193, 105245, 2020.

36. WANG L., QIU X.M., LIU Z.P., CHEN S.Y. Ecological efficiency of China's marine economy: A convergence analysis. Journal of Coastal Research. 94, 983, 2019.

37. KANG W.L., ZOU Y.K., WANG L., LIU X.M. Measurements and factors of biased technological progress in China's marine economy. Polish Journal of Environmental Studies. 29 (6), 4109, 2020.

38. SHEPHARD R.W. Cost and production functions. Princeton: Princeton University Press, 1953.

39. FÄRE R., GROSSKOPF S., NORRIS M. Productivity growth, technical progress, and efficiency change in industrial countries. The American Economic Review. 84 (1), 66, 1994.

40. FÄRE R., GRIFELL-TATJÉ E., GROSSKOPF S. Biased technical change and the Malmquist productivity index. Scandinavian Journal of Economics. 99 (1), 199, 1997.

41. WEBER W.L., DOMAZLICKY B.R. Total factor productivity growth in manufacturing: A regional approach using linear programming. Regional Science and Urban Economics. 29 (1), 105, 1999.

42. BARROS C.P., WEBER W.L. Productivity growth and biased technological change in UK airports. Transportation Research Part E-Logistics and Transportation Review. 45 (4), 642, 2009.

43. WANG Z.Y., YUAN F., HAN Z.L. Convergence and management policy of marine resource utilization efficiency in coastal regions of China. Ocean \& Coastal Management. 178, 104854, 2019.

44. WANG S.H., XING L., CHEN H.X. Impact of marine industrial structure on environmental efficiency. Management of Environmental Quality. 31 (1), 111, 2020.

45. CHEN Z.W., MA L. Research on spatial pattern and spatial effect of marine science and technology innovation efficiency in China's coastal provinces. Journal of Coastal Research. 54, 42, 2020. 